\title{
NOTA TÉCNICA \\ Reparación del emisario de Las Palmas de Gran Canaria. Parte II: simulaciones de vertido
}

\author{
Jesús CISNEROS AGUIRRE ${ }^{\mathbf{1}}$, Jon VILCHES SARASATE ${ }^{2}$, \\ María D. AFONSO CORREA ${ }^{3}$, Marc PIEDELEU ${ }^{1}$
}

1. Departamento de Física de la Universidad de Las Palmas de Gran Canaria, España. jcisneros@dfis.ulpgc.es

2. Experto en Ingeniería de Costas y Puertos. Las Palmas de Gran Canaria, España.

3. Pontho Ingeniería. Las Palmas de Gran Canaria, España.

\section{Resumen:}

Inicialmente la obra de reparación del emisario de Las Palmas de Gran Canaria se había programado sin incluir el tramo difusor. Esta nota técnica que describe una serie de simulaciones de diluciones de vertido, asociadas a diferentes situaciones del emisario durante su reparación, permitió demostrar a la administración la utilidad de un tramo difusor. El éxito de este estudio de simulaciones fue la claridad en la presentación de los resultados, de manera que resultó evidente a la administración los beneficios del tramo difusor respecto al incremento de tiempo y de presupuesto en la obra. Para obtener este resultado se requiere un conocimiento profundo de los particulares de la obra marítima y de la teoría académica aplicada, y además es necesario un contacto directo y continuo con los responsables de la administración. Estas dos notas técnicas (Parte I y Parte II) muestran una vía por la cual, a nuestro juicio, se deberían mover las Universidades y Centros de Investigación, para aumentar su utilidad directa en la sociedad.

Sometido el 29 de marzo de 2011, aceptado el 18 de julio de 2011, en línea el 31 de diciembre de 2012. La única versión revisada es la escrita en español. La o las otras versiones no habiendo sido examinadas por el comité de redacción de la revista, son publicadas bajo la completa responsabilidad de los autores. 


\section{Introducción}

En el año 2005 se decide por parte del Consejo Insular de Aguas de Gran Canaria la reparación del emisario de Las Palmas de Gran Canaria. Finalizada su construcción en 1992 presentaba un estado lamentable, varias roturas, deformaciones y estrangulamientos de la tubería, desplazamiento de tramos seccionados, deslizamiento y pérdida de muertos de flotación y sujeción. Las razones de ese estado y la descripción de los trabajos de reparación efectuados son presentados en la parte I de esta nota técnica (CISNEROS AGUIRRE \& AFONSO CORREA, 2012).

En un principio la obra de reparación se presupuesta y sale a subasta sin incluir el tramo difusor; la reparación se ejecuta cumpliendo tanto el tiempo de ejecución como el presupuesto, y cuando la obra estaba a punto de finalizar se presentó un estudio donde se propuso a la administración la ampliación del presupuesto y del tiempo de finalización, para incluir en la reparación el tramo difusor (CISNEROS AGUIRRE \& AFONSO CORREA, 2012).

El estudio, que se realizó en el Departamento de Física de la Universidad de Las Palmas de Gran Canaria, constaba de una recopilación teórica de la importancia del tramo difusor para incrementar la dilución de los vertidos, justificado con un resumen de las diferentes simulaciones numéricas de un modelo de dilución de vertidos, correspondientes a las diferentes situaciones posibles de la reparación. Incluía además un ajustadísimo plan de trabajo y un presupuesto muy detallado, ambos importantísimos para justificar los trabajos ante la admiración.

En esta nota técnica se discutirá el trabajo de modelización numérica, que consistió en simular tres situaciones diferentes de vertido:

- con el emisario antes de comenzar su reparación,

- con el emisario durante la etapa final de su reparación,

- con el emisario reparado incluyendo el tramo difusor.

\section{Metodología}

Para llevar a cabo las simulaciones fue utilizado el programa CORMIX (Cornell Mixing Zone Expert System) en su versión 4.1. CORMIX está avalado por la USEPA (U.S. Environmental Protection Agency) para la simulación de procesos de mezcla de vertidos al mar. Y es una herramienta muy útil en la minimización de los efectos producidos sobre el medio marino por parte de vertidos continuos y puntuales (JIRKA et al., 1996).

La metodología de CORMIX permite simular la práctica totalidad de las geometrías de descarga realizadas mediante una única boca así como con tramos difusores con varias aperturas tanto sumergidas como superficiales. Además permite predecir los procesos de mezcla para distintos tipos de descarga, salmuera de una desaladora, residuos sólidos urbanos, contaminación térmica debida a procesos industriales, aguas residuales 
urbanas; en diversos medios acuáticos, estuarios, océano abierto, ríos someros, etc. (BLENINGER \& JIRKA, 2006).

Las principales características del programa CORMIX son las siguientes:

- Incluye un estudio hidrodinámico completo, tanto en el campo cercano como en el lejano, de la trayectoria, concentración, forma, dilución y visualización de la pluma.

- Considera interacciones de la pluma con los bordes.

- Predice el comportamiento de corrientes debidas a la densidad.

- Provee un análisis documentado completo con todas las reglas usadas en la clasificación y las conclusiones logradas en cada sesión de trabajo.

- Incluye tres tipos de contaminantes tratados: conservativos, no conservativos, y de temperatura.

- Alerta cuando la pluma alcanza una zona de mezcla regulada restringida.

- Es aplicable a estados estacionarios, no estacionarios con corrientes o mareas y estancados.

- Puede predecir plumas atmosféricas en medios estratificados con velocidades sesgadas del viento.

\section{Casos de Simulación}

CORMIX está compuesto por varios sub-programas, DATIN, PARAM, CLASS, HYDRO y SUM, cada uno cumple su función dentro de CORMIX. DATIN es el módulo de entrada de datos e inicialización del resto de programas, PARAM usa los datos de entrada y calcula parámetros físicos y escalas importantes como precursor del siguiente programa, el CLASS, que realiza la clasificación hidrodinámica de la situación del ambiente y de la descarga que le hayamos introducido. HYDRO realiza la predicción numérica detallada de las características del efluente. SUM, resume los resultados de clasificación y predicción, los interpreta y sugiere variaciones en el diseño. Por último esta la salida gráfica. A continuación, en la figura 1, se presenta un cuadro resumen del funcionamiento de CORMIX.

Se han simulado tres casos, correspondientes a las tres fases de la obra de reparación:

- El primero con las condiciones del vertido al comenzar la obra.

- El segundo con las condiciones después de ser acabada la primera fase de la obra.

- El tercer caso con el emisario completamente reparado, realizando el vertido por el tramo difusor definido en el proyecto original de construcción.

Hay que aclarar que los emisarios son conductos que tienen como principal misión, además de alejar el vertido de la costa, la de lograr la máxima dilución de las sustancias vertidas. Actúan sobre el campo cercano, de manera que facilite al mar lo máximo posible la posterior disolución de las sustancias vertidas y su asimilación (ROBERTS et al., 1989a; ROBERTS et al., 1989b). 


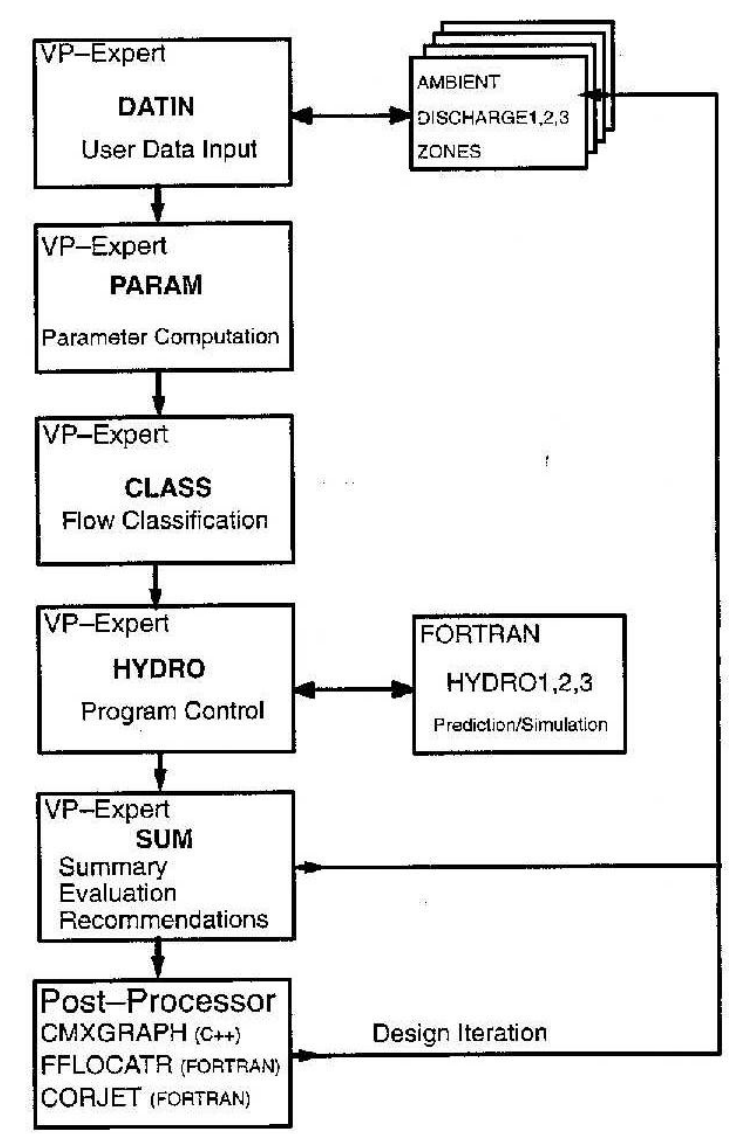

Figura 1. Descripción del funcionamiento del modelo CORMIX.

El mar tiene una gran capacidad para diluir y asimilar casi cualquier tipo de vertido biodegradable, pero vertidos muy concentrados, aunque sea de sustancias perfectamente asimilables como es el caso de los vertidos urbanos, impiden que el mar los disuelva y asimile de una manera rápida. Esto produce que un vertido casi en su totalidad compuesto de materia orgánica procedente de aguas urbanas, se convierta en un problema ecológico y sanitario, y contribuye a que sus efectos puedan incidir en la costa.

Las simulaciones se realizaron tomando como referencia un vertido de iguales características en los tres casos estudiados: un flujo de 600 l/s, con una concentración de $445 \mathrm{mg} / \mathrm{l}$ de un compuesto conservativo, vertido en el mar afectado por una corriente media de $0.3 \mathrm{~m} / \mathrm{s}$ en dirección hacia el Sur desplazando una mase de agua marina de $1.025 \mathrm{~g} / \mathrm{cm}^{3}$ de densidad. Estos valores del vertido son aproximados, esto porque la administración no considera oportuno publicar los datos reales de calidad y cantidad de vertido (en general, en ningún trabajo publicado, la administración comunica lo que vierte por un emisario). La corriente marina en la zona de estudio fue tomada uniforme reteniendo la velocidad máxima medida con un correntímetro tipo ADCP durante las campañas de campo que duraron solo unos pocos días. 
El trabajo se tuvo que hacer en tiempo record para poder entregar el estudio en tiempo para la modificación del presupuesto. Entre las diferentes simulaciones se modificaron únicamente las condiciones del punto de vertido que se diferencian únicamente en la profundidad y la distancia a la costa. En los dos primeros casos el vertido es por boca única. El tercer caso es igual que el segundo en cuanto a profundidad y distancia de la costa, pero el vertido es realizado por múltiples bocas, con las características del tramo difusor reparado totalmente. En la simulación del caso 3 no se incluyó el aumento de distancia y profundidad que proporcionaba el tramo difusor, ya que se quería evaluar los efectos del tramo difusor, comparando sus resultados con los del caso 2, con los mismos datos de profundidad de vertido.

La elección de un compuesto conservativo es debido a que de esta forma solo se tiene en cuenta la dilución física, debida a las condiciones del medio receptor y a las condiciones del vertido. No se contempla la capacidad del mar para asimilar e incorporar a sus cadenas tróficas otras sustancias que se vierten no conservativas, como nitratos, carbono orgánico particulado, carbono orgánico disuelto, bacterias, etc. Para lo cual haría falta un estudio de la zona de vertido más exhaustivo.

Se realizaron tres simulaciones para los tres casos previstos en las fases de la obra.

Caso 1: Caso del vertido con la rotura del emisario a 1810 metros de la costa y a 35 metros de profundidad.

Caso 2: Vertido por boca única a 2000 metros de la costa y 42 metros de profundidad.

Caso 3: Vertido por 20 difusores en los últimos 126 metros del emisario, a 2000 metros de la costa y 42 metros de profundidad.

El caso 1 correspondía al vertido del emisario con la rotura inicial. El caso 2 sería la simulación para el vertido en la primera fase de la reparación, es decir sigue siendo por boca única. Y el tercer caso representa la simulación del vertido con el tramo difusor como se diseñó en el proyecto inicial, con 20 difusores de $180 \mathrm{~mm}$ de diámetro espaciados cada 6 metros.

\section{Resultados}

La figura 2 muestra una fotografía aérea donde se puede apreciar la mancha en superficie del vertido después de la última rotura del emisario, lo que corresponde sensiblemente al caso 1 de las simulaciones. El curso de la tubería por el fondo es señalado con una línea. Los resultados del modelo indican que el vertido aflora en superficie con valores de la concentración de $3.62 \mathrm{mg} / \mathrm{l}$, y con un mínimo desplazamiento horizontal del punto de vertido a profundidad. Los valores de la concentración en los arcos de círculos concéntricos corresponden a distancias de 0, 140, 240, y 320 metros a partir del punto de afloramiento del vertido.

El vertido irrumpe en la superficie creando incluso una sobre-elevación, que produce una corriente de gravedad con un campo de presiones de gradientes tan elevados que hace que la mancha se extienda contra corriente durante varios centenares de metros 
(ver figura 2). La advección provocada por la corriente oceánica comienza a predominar sobre la dilución a una distancia de $300 \mathrm{~m}$ a partir del punto de vertido deformando la mancha superficial en dirección Sur. Esto da una idea clara del efecto desfavorable que produce el verter una gran cantidad de aguas residuales por un único punto de vertido.

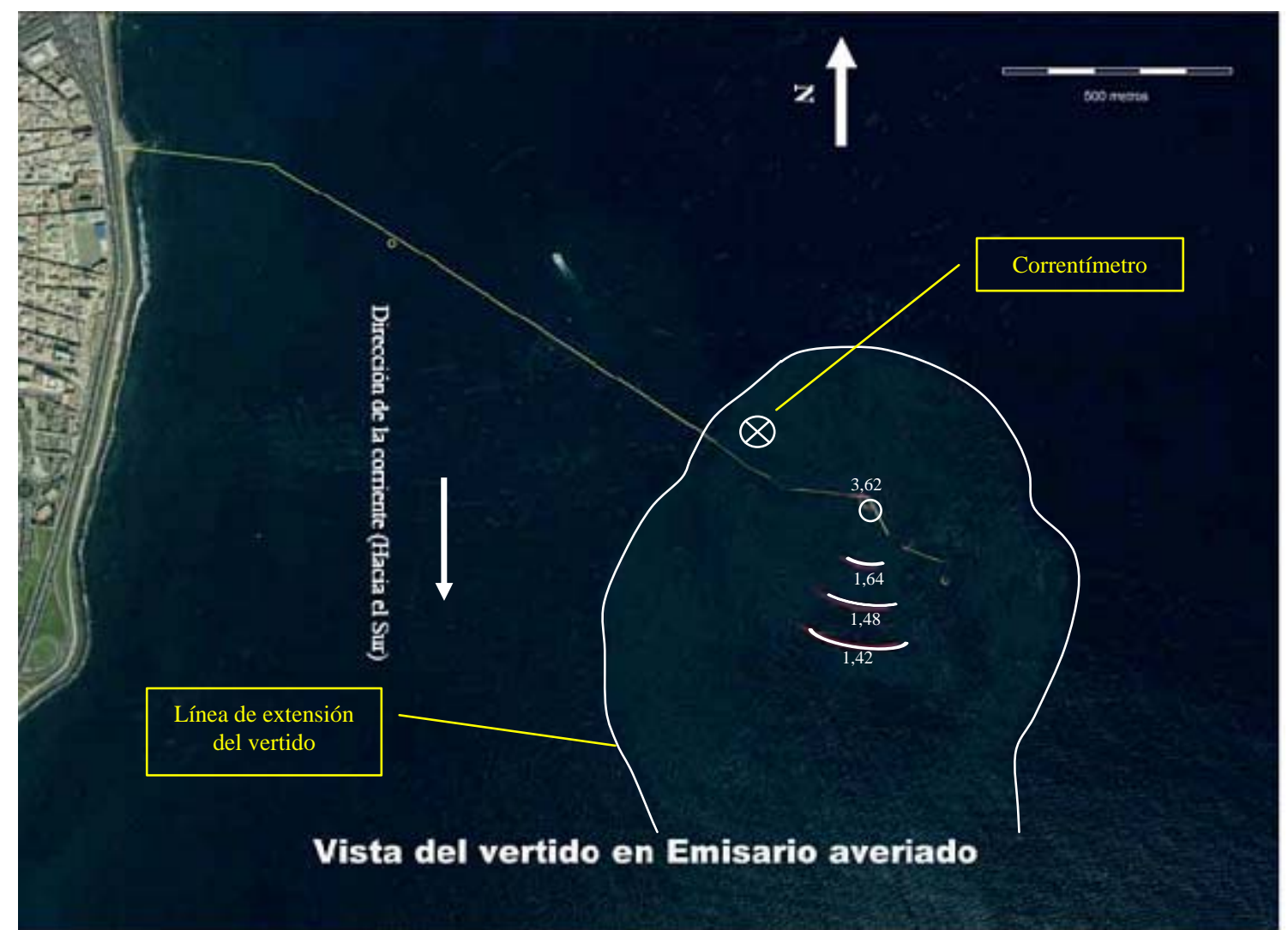

Figura 2. Fotografía aérea del vertido, con valores simulados de la concentración en superficie en el punto de vertido, y a 140, 240, y $320 \mathrm{~m}$ de ese punto (valores en mg/l).

Es necesario señalar que la fotografía puede no corresponder a la situación exacta de la simulación ya que se desconocen las condiciones de vertido y de corriente al momento de la toma. Sin embargo, esta fotografía si representa las condiciones normales del vertido, ya que la extensión de la mancha contra corriente por varios cientos de metros es una situación comprobada durante la realización de la obra. El modelo representa la dilución obtenida en superficie del vertido, pero debido a sus limitaciones no puede representar precisamente la extensión de la mancha, ni su evolución exacta.

En la figura 3 se muestra la salida gráfica del modelo numérico representando un perfil vertical alineado con la dirección Norte-Sur de la corriente. En una gradación de colores se muestran las concentraciones del vertido. Se puede observar como el penacho de la pluma sube a la superficie, casi verticalmente con poco efecto de la corriente circundante. 
Reparación del emisario de Las Palmas de Gran Canaria.

Parte II: simulaciones de vertido : 7.7

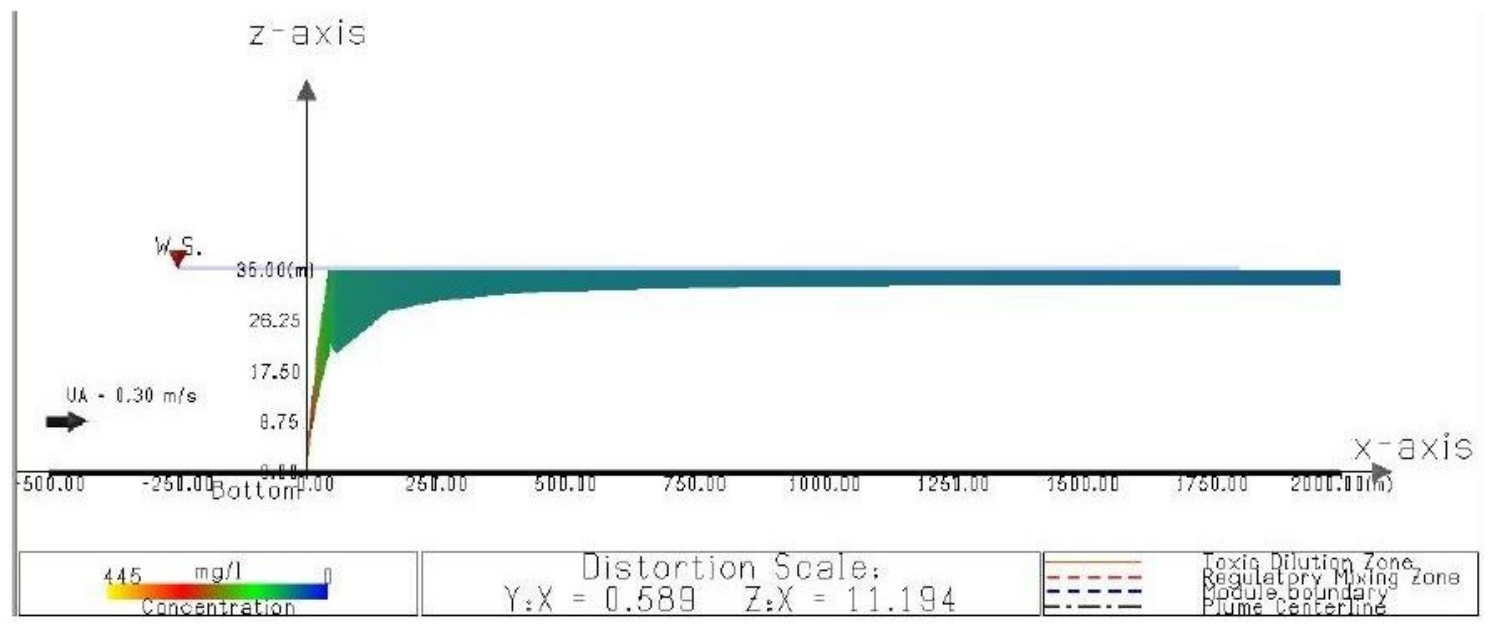

Figura 3. Simulación del vertido por boca única según el caso 2 (profundidad de $35 \mathrm{~m}$, distancia a la costa de $1810 \mathrm{~m}$ ), con una concentración inicial de 445 mg/l de sustancia conservativa y una corriente de $0.3 \mathrm{~m} / \mathrm{s}$.

La profundidad de la descarga es uno de los parámetros importantes en la dilución de un vertido y debido a esto cuando esta profundidad aumenta, la dilución aumenta, el vertido tiene un recorrido mayor en la columna de agua y se diluye más. Así, con la reparación de la primera fase de la obra y el vertido por boca única a 42 metros de profundidad y a 2000 metros de la línea de costa (caso 2 de las simulaciones) se logra una dilución en el punto de salida del vertido a superficie de 1.45 veces superior respecto a la correspondiente al caso 1 . La concentración en el punto de afloramiento tiene en efecto un valor de $2.50 \mathrm{mg} / \mathrm{l}$ (tabla 1). Los resultados del caso 2 (figura 4) guardan una similitud con los del caso 1 (figura 3).

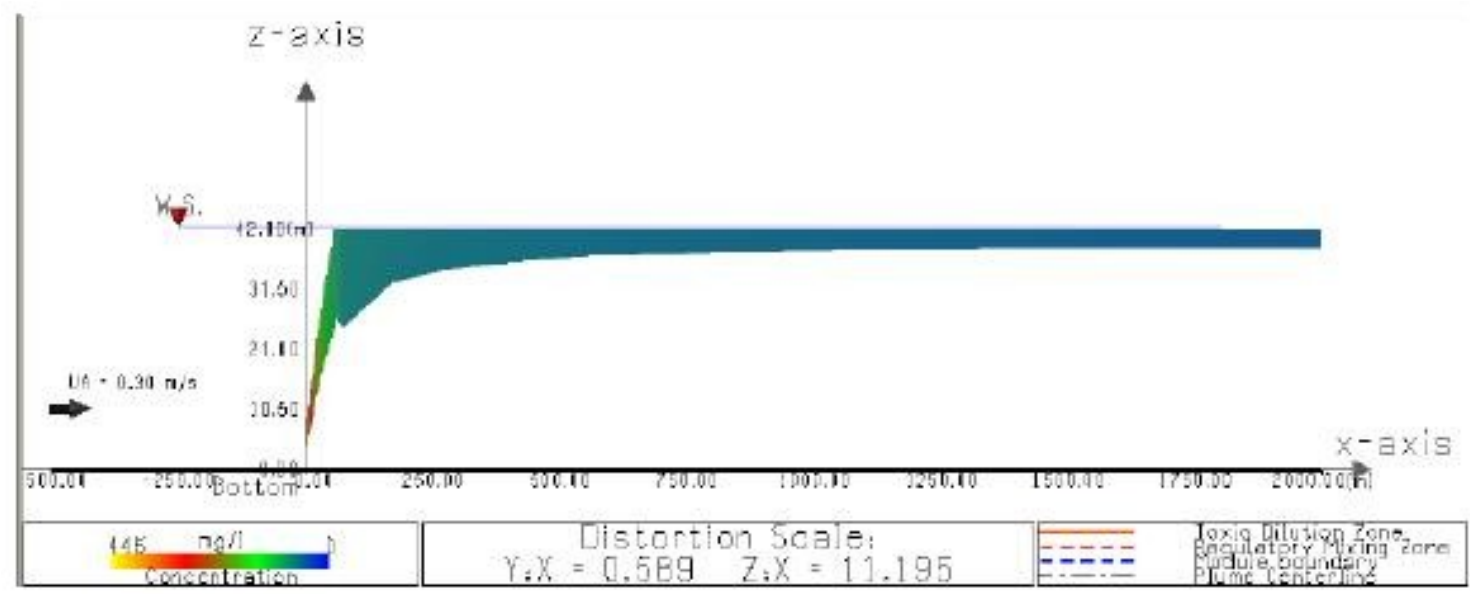

Figura 4. Simulación del vertido por boca única según el caso 2 (profundidad de $42 \mathrm{~m}$, distancia a la costa de $2000 \mathrm{~m}$ ), con una concentración inicial de 445 mg/l de sustancia conservativa y una corriente de $0.3 \mathrm{~m} / \mathrm{s}$. 
En este caso 2 se gana en dilución y se gana en alejamiento, dos parámetros que harán que el vertido tenga una mejor dispersión y que las consecuencias sobre la costa sean menores. Pero se puede comprobar que aunque existe mejora esta no es suficientemente importante.

\subsection{Efectos en campo cercano}

El tramo difusor es de 126 metros de longitud y vierte por 20 bocas alternadas de $180 \mathrm{~mm}$ de diámetro, situadas en los costados de la tubería, lo que tiene varios efectos sobre la pluma ascendente. Una revisión de los procesos que se producen en el campo cercano se ha discutido en FISHER et al. (1979), BROOKS (1983), JIRKA \& LEE (1994), BAUMGARTNER et al. (1993), y ROBERTS et al. (1989a; 1989b; 1989c).

La separación del efluente en 20 partes, hace que la superficie de contacto del medio receptor con el vertido sea mucho mayor y la mezcla tenga lugar con una mayor eficiencia.

Cada pluma individualmente realiza un efecto de incorporación de agua limpia, de manera que la sumatoria del agua incorporada al penacho ascendente será mucho mayor, que si solo se tiene un vertido con una única pluma. Esta rápida absorción de agua marina produce una disminución de la diferencia de densidad entre el vertido y el agua marina, lo que a su vez hace disminuir aún más la velocidad de ascensión.

En el caso 3 el vertido llega a superficie con una concentración de $0.321 \mathrm{mg} / \mathrm{l}$ (tabla 1), es decir 11.3 más diluido que en el caso 1 y 7.78 más que en el caso 2. La figura 5, presenta una salida gráfica del modelo de dilución donde se puede ver como el vertido sube lentamente y es desplazado por la corriente hacia el Sur desde prácticamente el punto de vertido (BLUMBERG et al., 1996; ZIELKE \& MAYERLE, 1999; BLENINGER \& JIRKA, 2006).

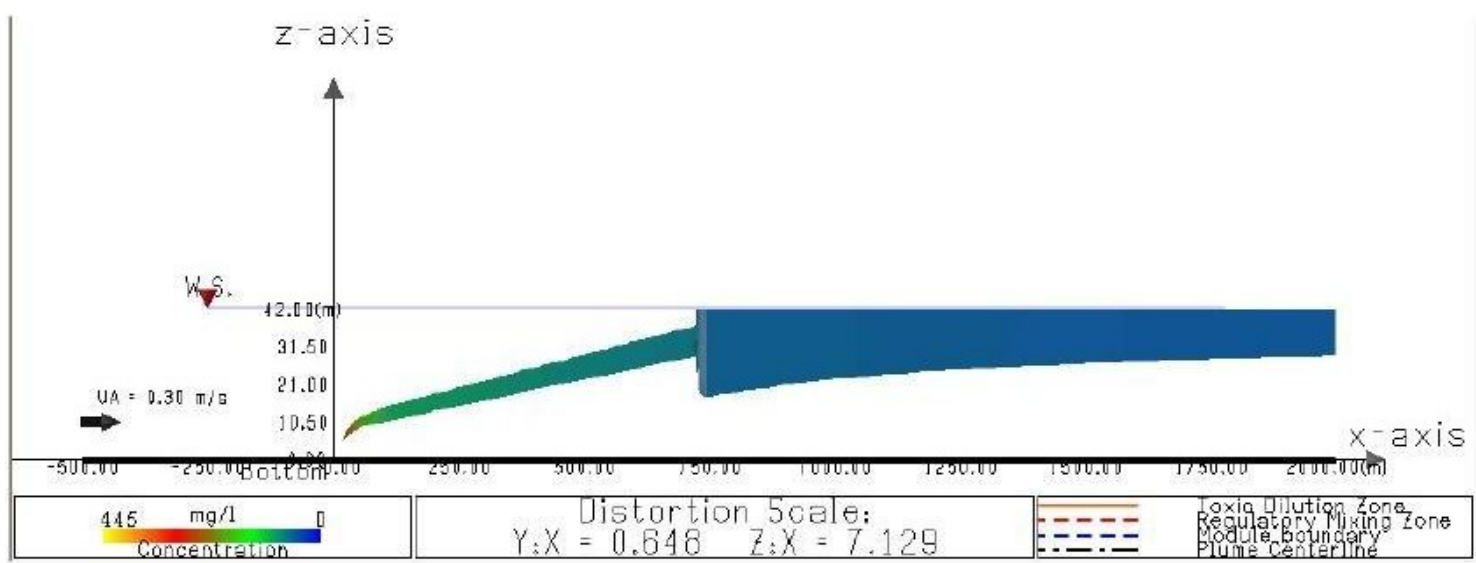

Figura 5. Simulación del vertido según el caso 2 (profundidad de $42 \mathrm{~m}$, distancia a la costa de 2000 m et vertido por 20 difusores en los últimos 126 metros del emisario), con una concentración inicial de $445 \mathrm{mg} / \mathrm{l}$ de sustancia conservativa y una corriente de $0.3 \mathrm{~m} / \mathrm{s}$. 
El vertido afloraría, siempre según la simulación, a unos 750 metros corriente abajo, con un tamaño de pluma mucho más grande que en las dos simulaciones anteriores. Lo que indica claramente que los difusores están influyendo mucho sobre el vertido y están haciendo que aumente decisivamente la longitud del penacho submarino, con un resultado de mezcla mucho mayor.

\subsection{Efectos en Campo Lejano}

En el campo lejano es muy importante tener un tamaño de mancha lo más grande posible. Una mancha mayor tendrá una dilución mucho más alta que una mancha pequeña para las mismas condiciones de dilución.

La Orden de 13 de Julio de 1993 (BOE -Boletín Oficial del Estado-, 1993) recomienda el uso de unas expresiones para el cálculo de los coeficientes de dispersión horizontal en dirección transversal a la pluma: $K_{y}\left(\mathrm{~m}^{2} / \mathrm{s}\right)=3 \times 10^{-5} \times B^{4 / 3}$, siendo $B$ el ancho inicial de la pluma expresado en metros.

El tamaño de la pluma de vertido al llegar a la superficie para el vertido realizado por los difusores del emisario completamente reparado (caso 3), es unas 10 veces mayor que para el vertido inicial del emisario roto (caso 1) y unas 7 veces mayor que para el vertido del emisario parcialmente reparado sin difusor (caso 2).

\section{Resumen de las simulaciones}

Las diluciones son del orden de más de 10 y casi 8 menos importantes en los casos 1 y 2, si comparamos los resultados con los del caso 3 que es cuando la reparación incluye el tramo difusor (tabla 1). Esta dilución inicial, de afloramiento a superficie, mucho mayor en el caso 3 hace que el tamaño de la pluma en superficie sea también mayor. Lo que provoca una mejora en la posterior dilución en el campo lejano.

Los cálculos de dilución para el ejemplo indican por sí solos la conveniencia de reparar el emisario hasta el final, con el tramo difusor según el diseño original del proyecto de construcción.

Tabla 1. Síntesis de los resultados relativos a la dilución correspondientes a las simulaciones de los 3 casos de vertido estudiados.

\begin{tabular}{|c|c|c|c|}
\hline $\begin{array}{l}\text { Distancia aguas abajo } \\
\text { a partir del punto de } \\
\text { afloramiento del }\end{array}$ & $\begin{array}{l}\text { Caso } 1 \\
\text { Emisario roto, vertido } \\
\text { a } 35 \text { m de profundidad }\end{array}$ & $\begin{array}{l}\text { Caso } 2 \\
\text { Boca única, vertido a } \\
42 \mathrm{~m} \text { de profundidad }\end{array}$ & $\begin{array}{l}\text { Caso } 3 \\
\text { Multidifusor, vertido a } \\
42 \mathrm{~m} \text { de profundidad }\end{array}$ \\
\hline vertido & Concentración (mg/l) & Concentración (mg/l) & Concentración (mg/l) \\
\hline $0 \mathrm{~m}$ & 3.62 & 2.50 & 0.321 \\
\hline $140 \mathrm{~m}$ & 1.64 & 1.18 & 0.213 \\
\hline $240 \mathrm{~m}$ & 1.48 & 1.07 & 0.207 \\
\hline $320 \mathrm{~m}$ & 1.42 & 1.02 & 0.203 \\
\hline
\end{tabular}




\section{Conclusiones}

Cada vez se está extendiendo más el uso de modelos numéricos para la ingeniería, y de una manera más intensa en la ingeniería costera. Hay que decir que a pesar del vertiginoso avance que han sufrido estas herramientas, están aún muy lejos de representar completamente la realidad de un proceso. El ejemplo que se presenta en esta nota técnica es claro a este respecto, el modelo no puede simular la extensión de la mancha en superficie y solo da una idea de la dilución en el punto de contacto con la superficie del agua.

Cada modelo tiene su rango de actuación, casi siempre muy restringido, que debe ser conocido por los utilizadores. Para que un modelo dé resultados fiables, se requiere una calibración de este con datos de campo de buena calidad (ZHANG 1995; ZHANG \& ADAMS, 1999). Por esta razón, las campañas de medida de campo deben ser planeadas y realizadas para que los datos de entrada y de calibración du modelo sean lo más precisos posible.

Las limitaciones du modelo CORMIX son grandes, por ejemplo, sólo admite una única velocidad de corriente en toda la columna. Sin embargo es un modelo que bien calibrado y con buenos datos de entrada para un determinado vertido, se convierte en una herramienta muy potente y fiable de gestión.

En este estudio el modelo ayudó a demostrar las mejoras en la dilución debido a la instalación del tramo multidifusor. El modelo sirvió para comparar tres casos posibles supuestamente similares entre los que la principal diferencia residía en la forma en que se realizaba el vertido, con todos los demás parámetros del medio ambiente permaneciendo constantes.

En la figura 6 se puede ver una foto aérea del vertido una vez realizada la reparación completa. Como se puede apreciar el vertido sigue desde su origen la corriente de agua, y se abre en penacho corriente abajo dejando una estela con una concentración en superficie mucho más baja que la inicial.

Se ha comprobado in situ como el vertido aflora mucho menos violentamente y se deja llevar por la corriente desde el principio. El olor y el color del agua han mejorado y el tamaño de la mancha en superficie ha aumentado considerablemente aunque es menos perceptible ya que llega mucho más diluida. 


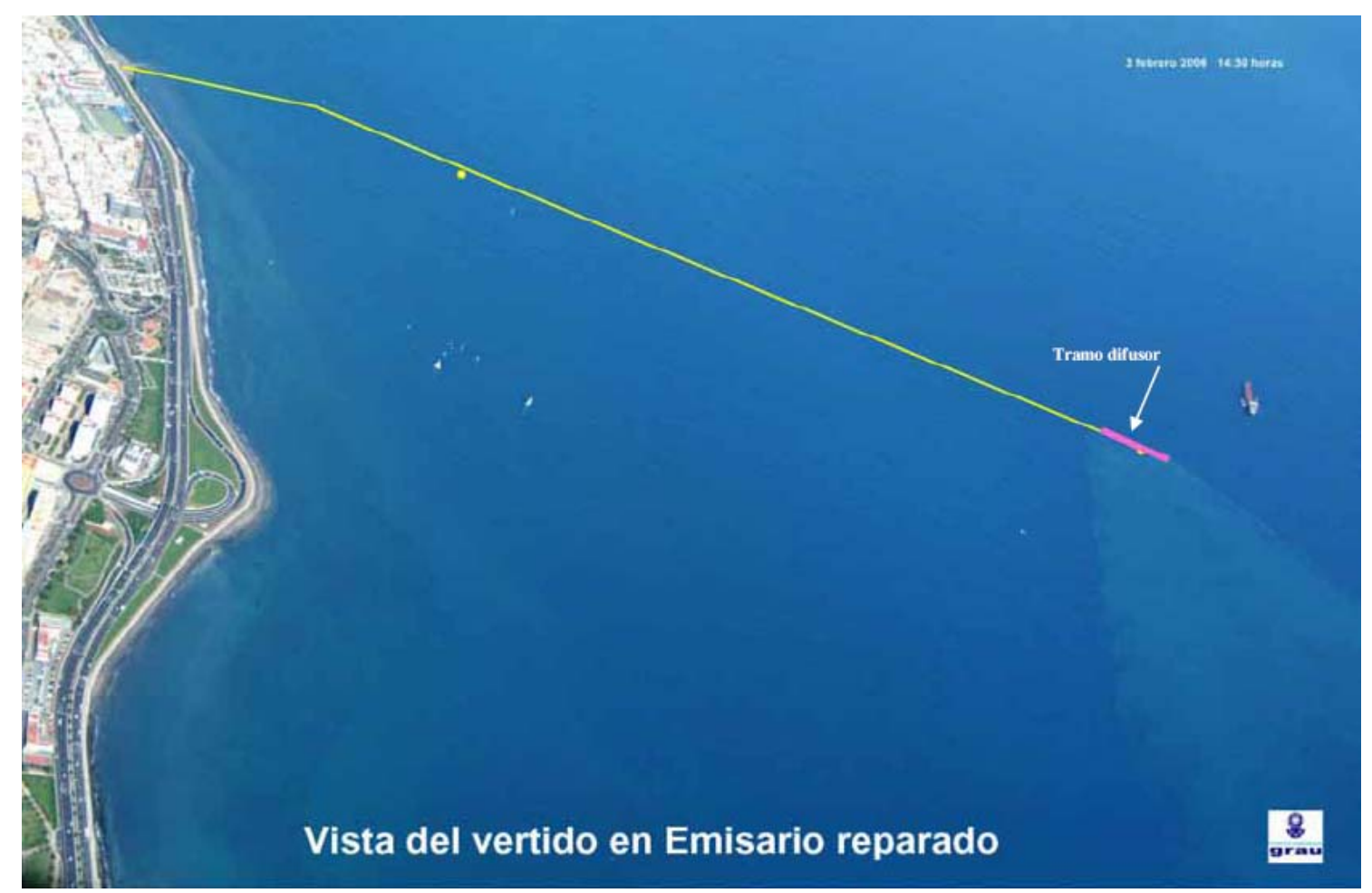

Figura 6. Vista aérea del vertido con el emisario reparado.

\section{Referencias bibliográficas}

BAUMGARTNER D.J., FRICK W.E., ROBERTS P.J.W. (1993). Dilution models for effluent discharges. Report No. EPA/600/R-93/139.

BLENINGER T., JIRKA G.H. (2006). Near and far-field model coupling methodology for wastewaters discharges. Institute for Hydromechanics, University of Karlsruhe, Germany.

BLUMBERG A.F., JI Z.G., ZIEGLER C.K. (1996). Modeling outfall plume behaviour using far field circulation model. Journal of Hydraulic Engineering, ASCE, Vol. 122, $n^{\circ}$ 11, pp 610-616. doi:10.1061/(ASCE)0733-9429(1996)122:11(610)

BOE -Boletín Oficial del Estado- (1993). Orden de 13 de julio de 1993 por la que se aprueba la instrucción para el proyecto de conducciones de vertidos desde tierra al mar. M. de Obras Públicas y Transportes, BOE nº 178 de 27/7/1993, pp 22861-22876, [URL http://www.boe.es/boe/dias/1993/07/27/pdfs/A22861-22876.pdf ]

BROOKS N.H. (1983). Dispersion in hydrologic and coastal environments. Environmental Protection Agency. Springfield, Virginia, NTIS, 141 p. PB-226980.

CISNEROS AGUIRRE J., AFONSO CORREA M.D. (2012). NOTA TÉCNICA - Reparación del emisario de Las Palmas de Gran Canaria. Parte I: descripción de los trabajos. Revue Paralia. Vol. 5, pp 6.1-6.20. doi:10.5150/revue-paralia.2012.006 FISHER H.B., LIST E.J., KOH R.C.Y., IMBERGER J., BROOKS N.H. (1979). Mixing in inland and coastal waters, Academic Press, New York. 
JIRKA G.H., LEE J.H.-W. (1994). Waste disposal in the Ocean, in Water Quality and its Control, M. Hino (ed.), Balkema, Rotterdam.

JIRKA G.H., DONEKER R.L., HINTON S.W. (1996). User's manual for CORMIX: A hydrodynamic mixing zone model and decision support system for pollutant discharges into surface waters. U.S. Environmental Protection Agency, Tech. Rep., Environmental Research Lab, Athens, Georgia, USA.

ROBERTS P.J.W., SNYDER W.H., BAUMGARTNER D.J. (1989a). Ocean outfalls I, Submerged wastefield formation. Journal of Hydraulic Engineering, ASCE, Vol. 115, pp 1-25. doi:10.1061/(ASCE)0733-9429(1989)115:1(1)

ROBERTS P.J.W., SNYDER W.H., BAUMGARTNER D.J. (1989b). Ocean outfalls II, Spatial evolution of submerged wastefield. Journal of Hydraulic Engineering, ASCE, Vol. 115, pp 26-48. doi:10.1061/(ASCE)0733-9429(1989)115:1(26)

ROBERTS P.J.W., SNYDER W.H., BAUMGARTNER D.J. (1989c). Ocean outfalls III, Effect of diffuser design on submerged wastefield. Journal of Hydraulic Engineering, ASCE, Vol. 115, pp 49-70. doi:10.1061/(ASCE)0733-9429(1989)115:1(49)

ZHANG X.-Y. (1995). Ocean outfall modeling - Interfacing near and far field models with particle tracking method. Dissertation thesis, Massachusetts Institute of Technology, Boston, USA.

ZHANG X.-Y., ADAMS E.E. (1999). Prediction of near field plume characteristics using far field circulation model. Journal of Hydraulic Engineering, ASCE, Vol. 125, n 3, pp 233-241. doi:10.1061/(ASCE)0733-9429(1999)125:3(233)

ZIELKE W., MAYERLE R. (1999). Küstengewässer, in: Numerische Modelle von Flüssen, Seen und Küstengewässer, W. Zielke [Hrsg.], DVWK Schriften 127, Bonn. 